\section{Employee Acceptance of INH Prophylaxis}

\section{To the Editor:}

Noteworthy in Price, Rutala and Samsa's article "Tuberculosis in Hospital Personnel" (1987; 8(3):97-101) was the wide variation in employee acceptance of isoniazid (INH) prophylaxis, ranging from $33 \%$ to $80 \%$. To me, there is limited value to discovering that an employee has become infected with $M$ tuberculosis if prophylaxis is not administered. My own bias is that employee acceptance of prophylaxis is influenced by convenience of administration and appropriate education of the employee. Do the authors have any information as to whether the hospitals with high INH prophylaxis acceptance rates have inhospital (as opposed to referral to Public Health Department) INH clinics?

Robert M. Lumish, MD

Chief, Division of Infectious Diseases/ Infection Control Mercy Hospital of Pittsburgh Pittsburgh, Pennsylvania

Ms. Price responds to Dr. Lumish:

My coauthors and I thank Dr. Lumish for his thoughtful question regarding health care worker acceptance of INH treatment. We certainly agree that the intent of tuberculosis surveillance is to recognize tuberculosis infection and administer treatment to prevent development of active disease.
We have no reported data in our study regarding acceptance of INH therapy and Dr. Lumish's question addresses our citation of previously published reports of hospital tuberculosis control programs. ${ }^{1-4}$ Ruben $^{1}$ and Vogeler ${ }^{2}$ both experienced low acceptance of preventive therapy. Ruben reported that great efforts were made to educate convertors regarding preventive treatment, but $86 \%$ of the subjects refusing treatment were over age 35 and expressed concern regarding drug-induced hepatitis. Atuk ${ }^{3}$ and Gregg ${ }^{4}$ both experienced good acceptance of preventive treatment. Both report well developed programs in which employees prescriptions were filled by the hospital pharmacy or provided free of charge and subjects were closely monitored at regular intervals throughout the course of treatment. Although it has not been carefully evaluated, these reports appear to support Dr. Lumish's hypothesis that (in the absence of medical contraindications) appropriate education and on-site management of convertors could positively influence compliance with therapy.

\section{REFERENCES}

1. Ruben FL, Norden CW, Schuster N: Analysis of a community hospitat employee tuberculosis screening program 31 months after its inception. Am Rev Respir Dis 1977, 115:23-28.

2. Vogeter DM, Burke JP: Tuberculosis screening for hospital employees: A five year experience in a large community hospital. Am Rev Respir Dis 1978; 117:227-292.

3. Atuk NO, Hunt EH: Serial tuberculin testing and isoniazid therapy in general hospital employees. JAMA 1971; 218:1795-1798.

4. Gregg DB, Gibson MS: Employee tuberculosis control in a predominantly tuberculosis hospital. J SC Med Assoc 1975 ; 5:I60-165.
Editorial note:

When rereading "Tuberculosis in Hospital Personnel" (Infect Control 1987; 8(3):97-101) the authors noted an error. The Mantoux method involved intradermal administration of $0.1 \mathrm{~mL}$ of Tweenstabilized PPD containing $5 T U$ not 0.01 $m L$ as indicated. The authors regret the error:

Loraine Price, BSN, CIC Division of Infectious Diseases University of North Carolina School of Medicine Chapel Hill, North Carolina

\section{MRSA Colonization}

\section{To the Editor:}

Bacon et al have reported a study of patients and personnel colonized with methicillin-resistant Staphylococcus aureus (MRSA) over a six-month period. ${ }^{1}$ Their findings emphasize the complexity involved in studying the spread of this organism. They treated personnel (but not patients) having MRSA nasal carriage with trimethoprim-sulfamethoxazole plus rifampicin for ten days. Their methods of detecting carriers before and after therapy involved streaking "cotton-tipped" applicators to nonselective TSA containing $5 \%$ sheep blood and then trying to isolate MRSA (details not given) from these plates. Several carriers persisted or became recolonized with the same or "different" strains of MRSA. 
The dangerous implication of this study is that such attempts to control outbreaks of MRSA may be futile. Perhaps such is the case, but before we concede that we are impotent to contain a nationwide MRSA epidemic, we must scrutinize the methodology in studies like that of Bacon et al. We feel the following points are worth considering:

1. Rectal, vaginal, or other-site carriage may explain apparent "persistence" or relapse of nasal carriage with MRSA. Personnel identified as nasal carriers should have other sites cultured to document the possibility of reimplantation into the nose of the MRSA strain.

2. MRSA may colonize the nose in variable numbers. ${ }^{2}$ Furthermore, MRSA usually shares the niche of the nasal mucosa with methicillin-susceptible $S$ aureus. Screening for nasal MRSA may best be accomplished by plating nasal swabs to media such at Staphylococcal 110 agar (Difco, Detroit, MI) with and without $12.5 \mu \mathrm{g} /$ $\mathrm{mL}$ methicillin. In this fashion, the ratio of MRSA to other staphylococci can be determined.

3 . Phage typing may not be an adequate method to separate strains. More sensitive methods such as determining the plasmid content ${ }^{3}$ or analyzing labeled proteins ${ }^{4}$ should be used.

4. Patient carriers should be identified before discharged and isolated upon readmission. The effect of control measures may take more than several months to become apparent. It is not clear what constitutes a successful control program. ${ }^{5}$

Hospital infection control teams around our country are probably at a loss to decide the best approach to control MRSA. The study of Bacon et al does not aid our strategy since the lack of rigorous methods leaves many questions unanswered. For instance, at their Michigan hospital, do they currently attempt to decolonize MRSA nasal carriage in medical and nursing personnel? At our institutions, we have good evidence of interhospital transmission by medical personnel. Thus, until definitive studies show that carriage of MRSA among personnel is not related to the transmission, we contend that hospital personnel with patient contact who are MRSA carriers should be decolonized.

\section{REFERENCES}

1. Bacon AE, Jorgensen KA, Wilson KH, Kauffman CA: Emergence of nosocomial methicillin-resistant Staphylococcus aureus and therapy of colonized personnel during a hospitalwide outbreak. Infect Control 1987; 8:145-150.

2. Suarez W, John JF: Relationship of methicillin-resistant Staphylococcus aureus nasal carriage to MRSA colonization and infection. 24th Interscience Conference on Antimicrobial Agents and Chemotherapy. American Society for Microbiology. 8-10 October 1984, Washington, D.C.

3. Kozarsky PE, Rimland D, Terry PM, Wachsmuth K: Plasmid analysis of simultaneous nosocomial outbreaks of methicillin-resistant Staphylococcus aureus. Infect Control 1986; $\mathbf{5 7 7 . 5 8 1 .}$.

4. Stephenson JR, Cook SJ, Tabaqchali S: New method for typing Staphylococcus aureus resistant to methicillin based on sulphur-35 methionine labelled proteins: its application in an outbreak. Br Med J 1986; 293:581-583.

5. Suarez W, John JF: The scope of nosocomial methicillinresistant Staphylococcus aureus. J Nosacomial Inf 1984; 1:9-16.

Joseph F. John, Jr., MD Annette C. Reboli, MD Veterans Administration Medical Center and Medical University of South Carolina Charleston, South Carolina

\section{Validity of Water Temperature Study Questioned}

\section{To the Editor:}

Smith et al ${ }^{1}$ reported on the effect of water temperature on bacterial killing in laundry in the May 1987 issue of
Infection Control. They used an impression plate method to determine bacterial flora on fabric. They did not discuss their choice of this method.

The efficiency of an impression plate method for this purpose is in fact low and the variation range high. In a comparative study of three methods to assess bacterial counts on fabrics, Hoborn and Nyström ${ }^{2}$ found that the geometric average of contact plate counts in three sets of experiments were ten- to a thousand-fold lower than those obtained with two homogenization methods. Thus, low temperature washing processes for hospital laundry should be validated with more efficient methods than impression plates, eg, a homogenization method.

Using textile pieces artificially contaminated with enterococci (Streptococcus faecalis NCTC 10927) and a homogenization method, Nyström ${ }^{3}$ demonstrated an inactivation factor around $10^{4}$ for a wash process at $50^{\circ} \mathrm{C}$, whether the process was with water only or with the addition of a detergent, and around $10^{6}$ when an alkalization to a $\mathrm{pH}$ above 11 and a subsequent neutralization with acid was added to the process. The effect of bleach was not assessed in the study because bleach was not always used in the laundry where the study was performed.

\section{REFERENCES}

1. Smith JA, Neil KR, Davidson CG, et al: Effect of water temperature on bacterial killing in laundry. Infect Control $1987 ; 8: 204-209$.

2. Hoborn J, Nyström B: Bacterial counts on fabrics: A comparative study of three methods. I Hyg Gamb 1985: 95:403-407.

3. Nyström B: Können Kittel aus Polyester/Baumwolle bei 70 Grad C sicher gewaschen werden? Hospital-Hygiene 1975: 12:418-421.

Bertil Nyström

Department of Clinical Bacteriology Huddinge Hospital Stockholm, Sweden 